\title{
Association between the APOE gene polymorphism and lipid profile and the risk of atrial fibrillation
}

\author{
Xunwei Deng ${ }^{1,2,3,4}$, Jingyuan Hou ${ }^{1,2,3,4}$, Qiaoting Deng ${ }^{1,2,3,4}$ and Zhixiong Zhong ${ }^{2,3,4,5,6^{*}}$ (D)
}

\begin{abstract}
Background: The relationship between the APOE gene polymorphism and lipid profiles and atrial fibrillation (AF) remains controversial. The current study purposed to investigate how the APOE gene SNPs (rs429358 and rs7412) and lipid profile are associated with the risk for AF among the Hakka population in southern China.

Methods: Finally, 1367 patients were enrolled in this study, including 706 participants with AF (41 98 years old, $58.64 \%$ male) and 661 non-AF subjects (28 95 years old, $59.46 \%$ male). The collected data included baseline characteristics, medical history, laboratory tests and echocardiography parameters. A general linear model (two-way analysis of variance (ANOVA)) and Tukey post-hoc tests were applied to identify an APOE allele, AF group, and interaction effect on lipid profiles. Logistic regression analysis was performed to identify risk factors for AF.

Results: For AF group, the most common genotype was E3/E3 (53.82\%), followed by E3/E4 (28.19\%), E2/E3 (13.60\%), E4/E4 (1.98\%), E2/E4 (1.84\%) and E2/E2 (0.57\%). The two-way ANOVA followed by the Tukey procedure showed the following: the lipid levels depended significantly on AF and APOE allele groups for TG, TC, LDL-C and Apo-B (all $P<0.001$ ), and statistically significant interactions between AF and APOE allele were observed in the above 4 variables (all $P<0.05$ ). Multivariate regression analysis indicated that age $\geq 65$ years $(P<0.001$ ), high diastolic blood pressure (DBP $\geq 90 \mathrm{~mm} \mathrm{Hg}, P=0.018)$, a high levels of total cholesterol $(T C \geq 5.2 \mathrm{mmol} / \mathrm{L}, P<0.001)$ and triglyceride ( $T G \geq 1.7 \mathrm{mmol} / \mathrm{L}, P=0.028$ ), but not the two SNPs of the APOE gene (rs7412 and rs429358) (OR 1.079, $P=0.683$ ), were significant independent risk factors for AF in the study population.

Conclusions: The principal findings of this study showed that individuals at high risk for AF were those over 65 years of age, higher DBP as well as high levels of TC and TG among the southern China Hakka population. The levels of TG, TC, LDL-C and Apo-B depended significantly on AF and APOE allele groups, and statistically significant interactions between AF and APOE allele were observed in the above 4 variables, although the APOE gene SNPs (rs429358 and rs7412) were no significant risk for AF incidence. Further investigation is needed to elucidate whether other SNPs of the APOE gene have a bearing on AF incidents.
\end{abstract}

Keywords: Apolipoprotein E, gene polymorphism, atrial fibrillation, Hakka, Southern China

\footnotetext{
* Correspondence: zhongzhixiong@mzrmyy.com

${ }^{2}$ Guangdong Provincial Key Laboratory of Precision Medicine and Clinical Translational Research of Hakka Population, Meizhou, P. R. China

${ }^{3}$ Guangdong Provincial Engineering and Technology Research Center for Molecular Diagnostics of Cardiovascular Diseases, Meizhou, P. R. China

Full list of author information is available at the end of the article
}

(C) The Author(s). 2021 Open Access This article is licensed under a Creative Commons Attribution 4.0 International License, which permits use, sharing, adaptation, distribution and reproduction in any medium or format, as long as you give appropriate credit to the original author(s) and the source, provide a link to the Creative Commons licence, and indicate if changes were made. The images or other third party material in this article are included in the article's Creative Commons licence, unless indicated otherwise in a credit line to the material. If material is not included in the article's Creative Commons licence and your intended use is not permitted by statutory regulation or exceeds the permitted use, you will need to obtain permission directly from the copyright holder. To view a copy of this licence, visit http://creativecommons.org/licenses/by/4.0/. The Creative Commons Public Domain Dedication waiver (http://creativecommons.org/publicdomain/zero/1.0/) applies to the data made available in this article, unless otherwise stated in a credit line to the data. 


\section{Background}

Atrial fibrillation $(\mathrm{AF})$ represents the most prevalent type of cardiac arrhythmia. The prevalence of AF has rapidly increased and is estimated to surpass 25 million cases by 2045 in China [1]. Since AF significantly contributes to mortality and health burden worldwide, it is of vital significance to study its underlying pathophysiological mechanisms. Over the past few decades, plenty of research works have investigated the clinical features and mechanisms of AF [2, 3]. The reported results indicated that the AF mechanism might be related to oxidative stress [4], inflammation [5] as well as electrical and structural remodeling of the atria [6]. Based on the close association between $\mathrm{AF}$ and other cardio-cerebrovascular diseases (e.g., heart failure, thromboembolism and stroke), there might be a potential correlation between their pathomechanisms. Hence, exploring the potential link between AF and the levels of blood lipid, which represent a wellestablished risk factor for cardio-cerebrovascular events, may provide a new perspective to identify the mechanism of AF and optimize the management of AF patients.

Dyslipidemia is deeply at risk for cardiovascular diseases $[7,8]$. The alteration of lipid metabolism is a representative feature in the incident and evolvement of atherosclerosis [9]. Long-term hyperlipidemia damages the artery intima and promotes atherosclerosis through the inflammatory-fibroproliferative reaction, eventually leading to severe cardiovascular events, such as coronary heart disease, heart failure and stroke. There is increasing evidence that the occurrence of $\mathrm{AF}$ is linked to the lipid profile, including the epicardial fat [10], pericardial fat, intrathoracic fat, abdominal visceral fat and body mass [11]. In the epicardial region of the heart, epicardial progenitor cells play a key role in the occurrence of arrhythmic events, which can be transformed into adipocytes under various stimuli [12].

Apolipoproteins play a leading role in lipid transport and in maintaining the balance of lipid metabolism [13]; they are closely related to lipid disorders. Apolipoprotein $\mathrm{E}$ (ApoE) is a polymorphic protein and generates six genotypes (E3/E3, E3/E4, E2/E3, E4/E4, E2/E4 and E2/E2). These genotypes are determined by rs429358 and rs7412 SNPs of the APOE gene, which exists in three major isoforms and has 3 allelic variants $(\varepsilon 2, \varepsilon 3$ and $\varepsilon 4)$ [13]. In southern China, approximately $65 \%$ of the Hakka population carry a common E3/E3 genotype [14]. Previous studies have revealed that the $A P O E$ \&4 allele is an established genetic risk factor for coronary heart disease (CHD) [15], atherosclerosis and Alzheimer's disease [16] and influences the development of CHD. In addition, CHD patients with the APOE \&4 carrier were significantly correlated with the incidence of ischemic stroke [17]. In patients with Alzheimer's disease, APOE $\varepsilon 4$ carrier was discovered to lead to a significantly faster disease progression [18]. Moreover, evidence suggests that the long-term use of antipsychotics in $A P O E$ \&4 carriers can also severely decrease cognitive function [19]. However, the association between $\mathrm{AF}$ and the $A P O E$ genotype has not been adequately investigated.

The present study aimed to investigate the possible potential role of the $A P O E$ genotype distribution and lipid profile in AF in the Hakka population of southern China. The APOE gene polymorphism may impact $\mathrm{AF}$ development by altering the lipid profile. These findings may provide a practical way to enhance the primary health care strategy of AF patients.

\section{Subjects and methods Ascertainment of AF}

Two experienced cardiologists analyzed the standard twelve-lead resting electrocardiography (ECG) to ascertain the AF incidence. The ECG was analyzed back-to-back according to the European Society of Cardiology / European Association for Cardio-Thoracic Surgery (ESC/EACTS) guidelines: (1) absence of distinct P waves; (2) irregular R$R$ intervals; (3) an irregular ventricular response; (4) atrial cycle length, which is the time interval between two atria activation, of $<200 \mathrm{~ms}$.

Based on the 2020 ESC/EACTS guidelines for AF management [20], AF is classified to: paroxysmal, persistent, longstanding persistent and permanent, depending on the frequency and duration. Paroxysmal AF was defined as AF with spontaneous termination or that requires intervention to restore the sinus rhythm within 7 days, while persistent AF lasts longer than 7 days.

\section{Subjects}

A total of 1523 participants who visited Meizhou People's Hospital (Huangtang Hospital), Guangdong, China, from May 2016 to April 2021 were included in the study. The main inclusion criteria for the AF group were: (1) confirmed diagnosis of AF by attending physicians; (2) age 18 years or above; (3) complete information of the clinical laboratory data. The exclusion criteria were: (1) history of malignant tumors or autoimmune diseases; (2) severe infection, tuberculosis or metabolic syndrome; (3) major diseases that affect the metabolism of inflammatory factors and blood lipids; (4) severe hepatic or renal diseases; (5) missing information of the baseline variables or ECG; (6) currently receiving lipid-lowering treatment or agents except statins; (7) unable to fully participate in the survey for other reasons. Subjects with no evidence of AF on history or electrocardiogram were included in the non-AF group. Of these, participants with incomplete clinical data $(n=62)$, those who did not sign the informed consent $(n=38)$ and those with a history of malignant tumors $(n=56)$ 
were excluded from the study. Finally, a total of 1367 participants met the inclusion criteria (showed in Fig. 1).

All the participants had complete medical records, including alcohol intake, smoking status, $A P O E$ genotyping, systolic pressure, diastolic pressure and lipid profile outcomes. Hypertension was defined as a blood pressure (BP) exceeding 140/90 $\mathrm{mm} \mathrm{Hg}$ as the mean of 3 independent measures or a current antihypertensive therapy [21]. Diabetes was diagnosed as a $2 \mathrm{~h}$ post-load glucose value of $\geq$ $200 \mathrm{mg} / \mathrm{dl}(11.1 \mathrm{mmol} / \mathrm{l})$, a fasting blood glucose $\geq$ $126 \mathrm{mg} / \mathrm{dl}(7 \mathrm{mmol} / \mathrm{L})$ or a current treatment with antidiabetic medications. According to the Chinese adult dyslipidemia prevention guide (2016 edition), high TC was defined as total cholesterol (TC) $\geq 5.2 \mathrm{mmol} / \mathrm{L}$, high TG was defined as triglycerides (TG) value $\geq 1.7 \mathrm{mmol} / \mathrm{L}$, high LDL-C was defined as serum low-density lipoproteincholesterol (LDL-C) concentrations greater than 3.4 $\mathrm{mmol} / \mathrm{L}$, and low HDL-C was defined as a value of highdensity lipoprotein-cholesterol $(\mathrm{HDL}-\mathrm{C})<1.0 \mathrm{mmol} / \mathrm{L}$ [22]. The normal levels of the following indexes exhibited the following range: Apolipoprotein A1 (Apo A1) from 1 to $1.6 \mathrm{~g} / \mathrm{L}$; Lipoprotein a (Lp-a) from 0 to $30 \mathrm{mg} / \mathrm{mL}$; and Apolipoprotein B (Apo B) from 0.6 to $1.1 \mathrm{~g} / \mathrm{L}$ [23]. Atherosclerosis was defined as a complex pathological change that involves an excessive inflammatory response, hyperlipidemia, thrombus formation following injurious stimuli, plaque evolution and destabilization, leading to myocardial ischemia as well as necrotic or coronary artery disease. Heart failure was defined as a clinical syndrome with typical symptoms (e.g., breathlessness, fatigue), which may be accompanied by other manifestations (e.g., hypoxemia, pneumonedema) due to a structural and/or functional cardiac abnormality.

The study protocol was performed according to the ethical guidelines of the 1975 Declaration of Helsinki and approved by the institutional review board and ethical committee of the Meizhou Peoples' Hospital (No. MPH-HEC 2021-C-19). All patients provided written informed consent before taking part in the study.

\section{Sample collection}

All fasting blood sample was divided into two aliquots: one in an ethylenediaminetetraacetic acid (EDTA) vial and the other in a plain vial. DNA was extracted from the sample with EDTA, while the serum was used for biochemical analysis. The samples were stored at $-20{ }^{\circ} \mathrm{C}$ until being processed.

\section{Lipid analysis and clinical data acquisition}

Lipid analysis were performed for serum samples in two groups. The Beckman Coulter clinical chemistry autoanalyzer AU5400 was used to assay the TC, TG, HDL-C, LDL-C, apolipoprotein A1 (Apo-A1) and apolipoprotein B (Apo-B). Besides, the parameters of the alcohol intake and smoking status of participants were categorized into never, former or current. The systolic and diastolic pressure values were measured twice in a sitting position using a sphygmomanometer at 5-minute intervals after resting for at least $5 \mathrm{~min}$. In addition, the following data was collected: (1) demographic data (age, sex); (2) clinical laboratory data on the liver and kidney function, including alanine aminotransferase (ALT), aspartate aminotransferase (AST), urea nitrogen (UN), serum creatinine (Scr), uric acid (UA), C-reactive protein (CRP) and white blood cell (WBC); (3) echocardiographic results, including the left atrium diameter (LAD), left ventricular end-diastolic diameter (LVDd), left ventricular end-systolic diameter (LVSd) and left ventricular ejection fractions (LVEF); (4) personal medical history during a medical appointment. We gathered all demographic and clinical results from our hospital's computerized medical recording system.

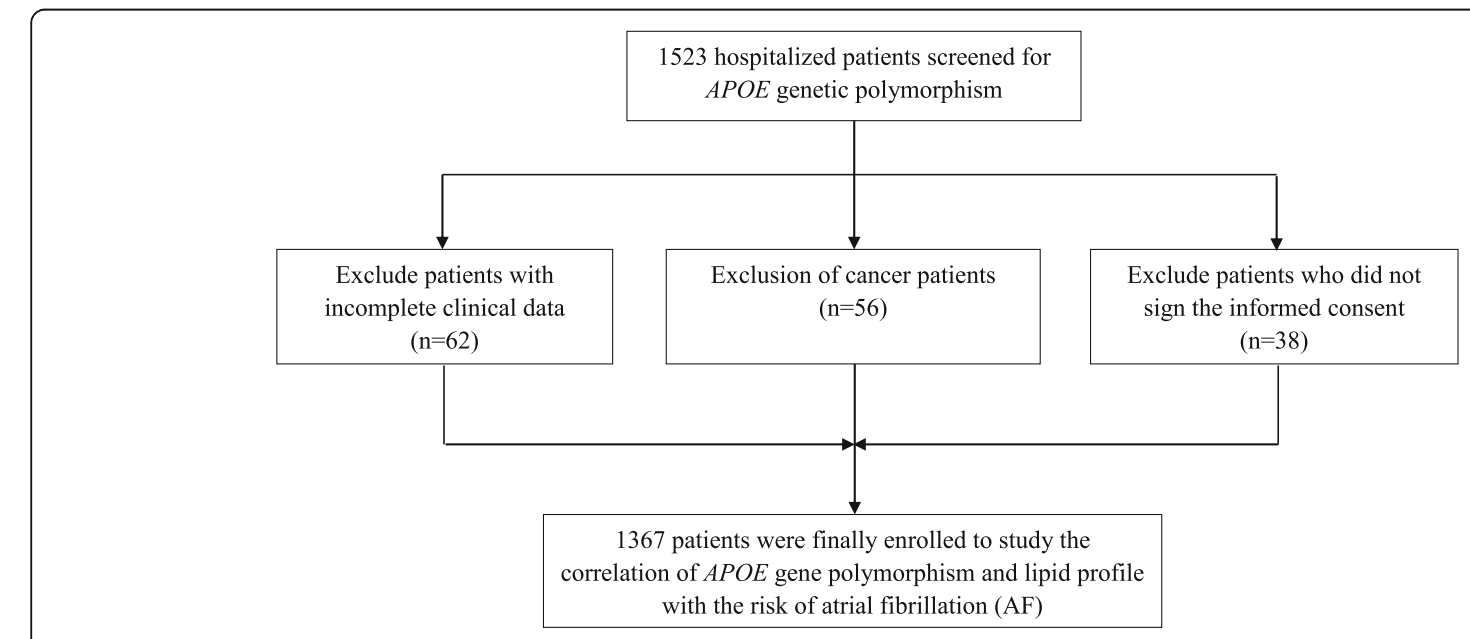

Fig. 1 Flow chart of investigating the correlation of APOE gene polymorphism and lipid profile with the risk of AF 


\section{APOE genotyping}

Genomic DNA was isolated from $2 \mathrm{ml}$ of whole peripheral blood samples of both groups using the QIAamp DNA Blood Mini Kit (Qiagen, Germany) following the manufacturer's protocol. A Nanodrop 2000 TM Spectrophotometer was used for DNA concentration and purity, with an A260/280 ratio > 1.7 considered to be qualified. The two SNPs of rs429358 (E4) and rs7412 (E2) of the $A P O E$ gene were determined using a commercial kit (LOT no. B50201013A, Sinochips Bioscience Co., Ltd, Zhuhai, Guangdong, China). Protocol for polymerase chain reaction (PCR) was as follow: $50{ }^{\circ} \mathrm{C}$ for $2 \mathrm{~min}$, predenaturation at $95{ }^{\circ} \mathrm{C}$ for $15 \mathrm{~min}$, followed by 45 cycles comprising of denaturing at $94{ }^{\circ} \mathrm{C}$ for $30 \mathrm{~s}$ and annealing at $65{ }^{\circ} \mathrm{C}$ for $45 \mathrm{~s}$. The amplified products were subsequently dispensed into a hybridization reaction chamber. The genotype was revealed using an $A P O E$ gene chip assay (Sinochips Bioscience Co., Ltd, Zhuhai, China) according to the manufacturer's instructions. For the genotyping quality control, blank tubes without DNA were included in all the SNPs that were analyzed as the negative control and confirmed by duplicate analysis of $10 \%$ of samples. Figure 2 shows the microarray results of the kit for six types of the $A P O E$ genotype.

Linkage disequilibrium (LD) figure and values were calculated with Haploview 4.2 (http://www. broadinstitute.org/scientific-community/science/ programs/medical-andpopulation- genetics/haploview/ haploview).

\section{Statistical analysis}

Statistical analysis was assessed with the IBM SPSS v.19 software. The Hardy-Weinberg equilibrium of the allele and genotype between-group differences was performed with the Chi-square test. The Kaplan-Meier method was used to evaluate the data normality. Measurement variables were represented as mean values \pm standard deviation (SD) and compared via unpaired Student's t-test or Mann-Whitney U test as appropriate. Categorical variables were expressed as a number (percent) and analyzed using the Chi-square test. A two-way ANOVA followed by Tukey post-hoc test, which included the factors $A P O E$ allele and $\mathrm{AF}$, was conducted to assess the effect of those on the levels of lipid profiles. Logistic regression analysis was conducted to investigate the associations of the risk factors related to the occurrence of $\mathrm{AF}$ and potential covariates. Two-sided $P$-value below 0.05 was regarded to be significant.

\section{Results}

\section{Clinical characteristics of the participants}

A total of 1367 individuals were included, among which 706 participants (292 women and 414 men) were patients with paroxysmal or persistent AF, aged $41 \sim 98$ years old and 661 participants (268 women and 393 men) without AF as controls, with an average age of (67.11 \pm 11.92$)$. Table 1 lists the baseline characteristics and medical history of all the participants. There was a significant difference in age, diastolic blood pressure (DBP), CAD and HF incidence between the AF and control groups. Patients with AF were older than those in the control group, had higher DBP, and had a higher incidence of CAD and HF (all $P<0.001$ ). Regarding the medical history, the prevalence of diabetes and hypertension was $29.18 \%$ and $60.06 \%$, respectively, in the AF group and $28.44 \%$ and $57.34 \%$, respectively, in the

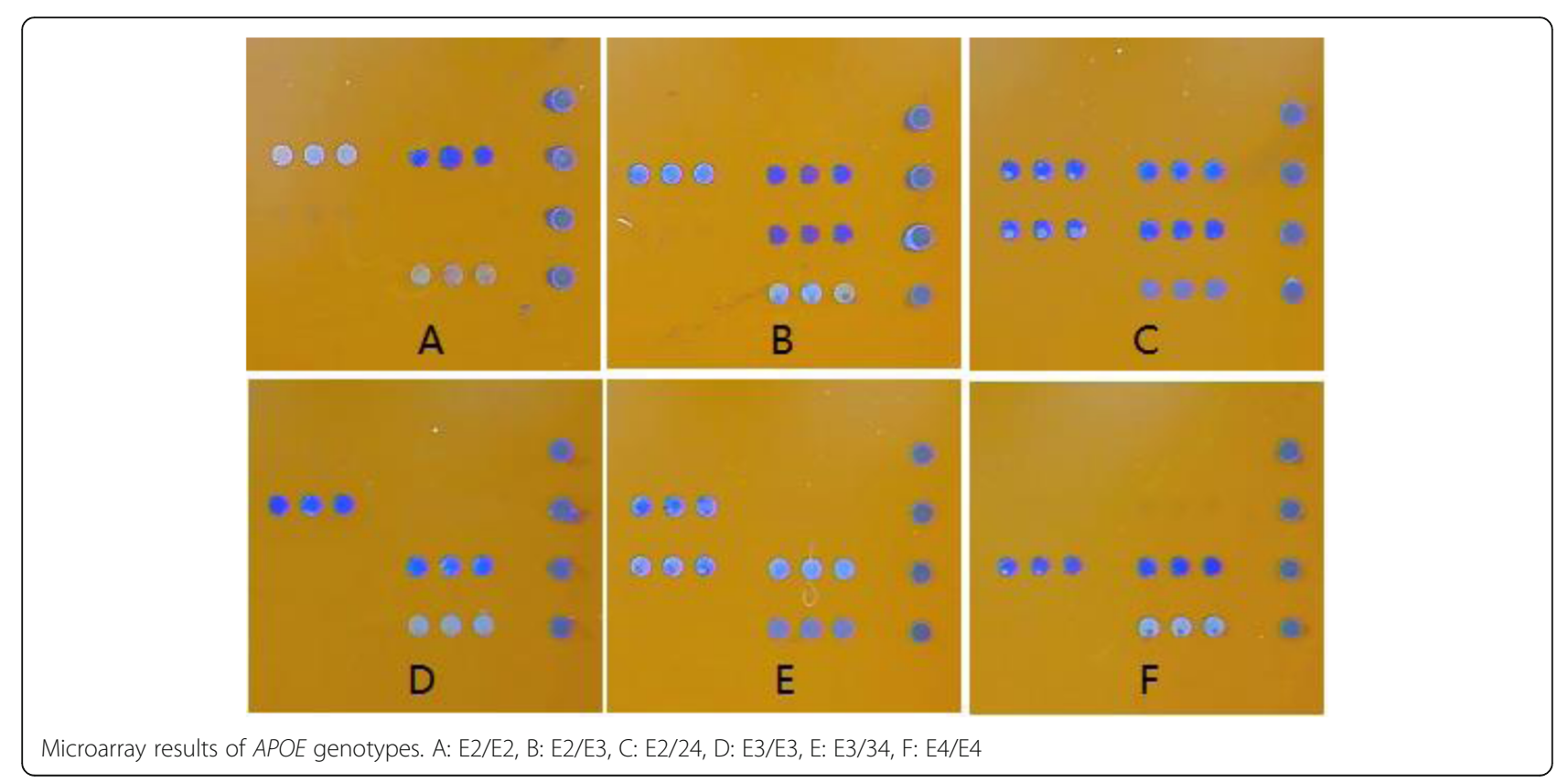


Table 1 Baseline characteristics, medical history and drug therapy of the study participants

\begin{tabular}{|c|c|c|c|}
\hline Variables & AF patients $(n=706)$ & Controls $(n=661)$ & $P$ \\
\hline \multicolumn{4}{|c|}{ Baseline characteristics, n (\%) } \\
\hline Age $\geq 65 y$ & $575(81.44)$ & $396(59.91)$ & $<0.001$ \\
\hline Male & $414(58.64)$ & 393(59.46) & 0.783 \\
\hline $\mathrm{SBP} \geq 140 \mathrm{~mm} \mathrm{Hg}$ & $329(46.60)$ & $307(46.44)$ & 0.954 \\
\hline $\mathrm{DBP} \geq 90 \mathrm{~mm} \mathrm{Hg}$ & $242(34.28)$ & $173(26.17)$ & $<0.001$ \\
\hline APOE- $\varepsilon 4$ carrier & $226(32.01)$ & $180(27.23)$ & 0.053 \\
\hline \multicolumn{4}{|l|}{ Alcohol intake } \\
\hline Never & 677(95.89) & $630(95.31)$ & 0.175 \\
\hline Former & $15(2.12)$ & $9(1.36)$ & \\
\hline Current & 14(1.98) & $22(3.33)$ & \\
\hline \multicolumn{4}{|l|}{ Smoking status } \\
\hline Never & $542(76.77)$ & 498(75.34) & 0.101 \\
\hline Former & $89(12.61)$ & 70(10.59) & \\
\hline Current & $75(10.62)$ & $93(14.07)$ & \\
\hline \multicolumn{4}{|c|}{ Medical history, n (\%) } \\
\hline Hypertension & $424(60.06)$ & $379(57.34)$ & 0.307 \\
\hline Diabetes & 206(29.18) & 188(28.44) & 0.764 \\
\hline CAD & $390(55.24)$ & 223(33.74) & $<0.001$ \\
\hline HF & 294(41.64) & 63(9.53) & $<0.001$ \\
\hline \multicolumn{4}{|c|}{ Drug Therapy, n (\%) } \\
\hline Statin & $16(2.27)$ & $12(1.82)$ & 0.556 \\
\hline ACEls & $190(26.91)$ & $111(16.79)$ & $<0.001$ \\
\hline ARBs & 148(20.96) & $149(22.54)$ & 0.479 \\
\hline BBs & $302(42.78)$ & 179(27.08) & $<0.001$ \\
\hline MRAs & 275(38.95) & $53(8.02)$ & $<0.001$ \\
\hline Digoxin & 197(27.90) & $24(3.63)$ & $<0.001$ \\
\hline Diuretics & $324(45.89)$ & $91(13.77)$ & $<0.001$ \\
\hline
\end{tabular}

Values for age expressed as mean \pm SD

SBP: systolic blood pressure

DBP: diastolic blood pressure

CAD: coronary artery disease

HF: heart failure

ACEls: angiotensin-converting enzyme inhibitors

ARBs: angiotensin receptor blockers

BBs: $\beta$-receptor blockers

MRAs: mineralocorticoid antagonists

control group. However, none of the prevalence in diabetes and hypertension differed across the two groups. Furthermore, no significant difference was found across the two groups regarding the factors of sex, systolic blood pressure (SBP), APOE $\varepsilon 4$ carrier, smoking status and alcohol intake. In the received medication, patients with AF took more ACEIs, BBs, MRAs, diuretics, and digoxin (all $P<0.001$ ).

The echocardiography results and laboratory data of the two groups are shown in Table 2. Overall, the patients in the AF group had significantly larger LAD, LVDd and LVSd, along with a significantly lower LVEF (all $P<0.001$ ). Regarding the levels of lipid profiles, the subjects in the AF group also had significantly higher levels of all parameters (all $P<0.001$ ), except for HDL-C and Apo-A1, compared with the control group. Nevertheless, the controls had significantly lower levels of ALT, AST, UN, Scr and UA (all $P<0.001$ ). Moreover, no significant differences in the CRP and WBC across the two groups.

\section{$A P O E$ genotype and allele frequencies}

The distribution of the $A P O E$ genotype and allele in the $\mathrm{AF}$ and control group is listed in Table 3 . In the AF group, the predominant genotype was E3/E3 (53.82\%), followed by E3/E4 (28.19\%), E2/E3 (13.60\%), E4/E4 
Table 2 Echocardiography results and laboratory data of the study participants

\begin{tabular}{|c|c|c|c|}
\hline Variables & AF patients $(n=706)$ & Controls $(n=661)$ & $P$ \\
\hline \multicolumn{4}{|l|}{ Echocardiography results } \\
\hline $\mathrm{LAD}, \mathrm{mm}$ & $40.23 \pm 8.40$ & $31.34 \pm 4.63$ & $<0.001$ \\
\hline LVDd, mm & $46.82 \pm 8.44$ & $43.95 \pm 5.75$ & $<0.001$ \\
\hline LVSd, mm & $33.85 \pm 9.17$ & $29.44 \pm 6.03$ & $<0.001$ \\
\hline LVEF, \% & $54.13 \pm 12.84$ & $62.20 \pm 8.37$ & $<0.001$ \\
\hline \multicolumn{4}{|l|}{ Laboratory data } \\
\hline $\mathrm{TC} \geq 5.2 \mathrm{mmol} / \mathrm{L}, \mathrm{n}(\%)$ & 178(18.13) & $48(7.26)$ & $<0.001$ \\
\hline $\mathrm{TG} \geq 1.7 \mathrm{mmol} / \mathrm{L}, \mathrm{n}(\%)$ & $167(23.65)$ & $96(14.52)$ & $<0.001$ \\
\hline HDL-C < 1mmol/L, n (\%) & 191(27.05) & $166(25.11)$ & 0.414 \\
\hline LDL-C $\geq 3.4 \mathrm{mmol} / \mathrm{L}, \mathrm{n}(\%)$ & 109(15.44) & $18(2.72)$ & $<0.001$ \\
\hline Apo-A1 $\geq 1.6$ g/L, n (\%) & $38(5.38)$ & $48(7.26)$ & 0.153 \\
\hline Apo-B $\geq 1.1$ g/L, n (\%) & $99(14.02)$ & $26(3.93)$ & $<0.001$ \\
\hline$A L T, U / L$ & $32.42 \pm 25.54$ & $26.80 \pm 20.05$ & $<0.001$ \\
\hline AST, U/L & $42.49 \pm 43.66$ & $29.83 \pm 27.88$ & $<0.001$ \\
\hline UN, mmol/L & $8.24 \pm 5.06$ & $6.46 \pm 3.30$ & $<0.001$ \\
\hline Scr, umol/L & $125.70 \pm 85.70$ & $102.51 \pm 70.39$ & $<0.001$ \\
\hline UA, umol/L & $412.45 \pm 145.89$ & $325.74 \pm 110.82$ & $<0.001$ \\
\hline CRP, mg/L & $46.59 \pm 57.46$ & $41.81 \pm 46.65$ & 0.302 \\
\hline WBC, $10^{9} / \mathrm{L}$ & $9.53 \pm 4.55$ & $9.04 \pm 4.44$ & 0.563 \\
\hline
\end{tabular}

LAD: left atrium diameter

LVDd: left ventricular end-diastolic diameter

LVSd: left ventricular end-systolic diameter

LVEF: left ventricular ejection fractions

TC: total cholesterol

TG: triglyceride

HDL-C: high-density lipoprotein cholesterol

LDL-C: low-density lipoprotein cholesterol

Apo-A1: apolipoprotein A1

Apo-B: apolipoprotein B

ALT: alanine aminotransferase

AST: aspartate aminotransferase

UN: urea nitrogen

Scr: serum creatinine

UA: uric acid

CRP: C-reactive protein

WBC: white blood cell

Table.3 The distributions of APOE genotypes and alleles in patients with AF and control groups

\begin{tabular}{llll}
\hline & AF patients $(\boldsymbol{n}=\mathbf{7 0 6})$ & Controls $(\boldsymbol{n}=\mathbf{6 6 1})$ & $\mathbf{X}^{\mathbf{2}}$ \\
\hline Genotype & $n=706$ & $n=661$ & $\boldsymbol{P}$ \\
E2/E2 & $4(0.57)$ & $5(0.76)$ & 5.32 \\
E2/E3 & $96(13.60)$ & $98(14.83)$ & 0.379 \\
E2/E4 & $13(1.84)$ & $14(2.12)$ \\
E3/E3 & $380(53.82)$ & $378(57.19)$ \\
E3/E4 & $199(28.19)$ & $151(22.84)$ & \\
E4/E4 & $14(1.98)$ & $15(2.27)$ \\
Allele & $n=1412$ & $n=1322$ \\
E2 & $117(8.29)$ & $122(9.23)$ & 3.01 \\
E3 & $1055(74.72)$ & $1005(76.02)$ & \\
E4 & $240(16.99)$ & $195(14.75)$ \\
Hardy-Weinberg equilibrium & $X^{2}=8.05$, & $X^{2}=1.38$, \\
& $P=0.090$ & $P=0.849$ & 0.222 \\
\hline
\end{tabular}


(1.98\%), E2/E4 (1.84\%) and E2/E2 (0.57\%). In the control group, the frequencies of genotypes E3/E3, E3/E4, E2/E3, E4/E4, E2/E4 and E2/E2 were 57.19, 22.84, 14.83, $2.27,2.12$ and $0.76 \%$, respectively.

The $A P O E$ genotypes were divided into the following three subgroups according to the alleles: $\varepsilon 2$ (E2/E2 and E2/E3), $\varepsilon 3$ (E3/E3) and $\varepsilon 4$ (E2/E4, E3/E3, and E3/E4). The frequencies of the $A P O E$ alleles $\varepsilon 2, \varepsilon 3$ and $\varepsilon 4$ were $8.29 \%, 74.72 \%$ and $16.99 \%$, in AF patients and $9.23 \%$, $76.02 \%$ and $14.75 \%$ in the control subjects, respectively. In both groups, the distribution of the $A P O E$ polymorphism genotypic frequencies followed the HardyWeinberg equilibrium. There was no evidence about the frequency of the $A P O E$ genotypes and alleles differed across the two groups. $(P=0.379$ and $P=0.222$, respectively).

\section{Linkage disequilibrium}

The LD between the APOE rs429358 and rs7412 polymorphisms was evaluated (Fig. 3), the two SNPs were not in perfect $\mathrm{LD}\left(\mathrm{r}^{2}=0.018\right)$. So the analysis of all polymorphisms was investigated.

\section{$A P O E$ allele, AF and lipid levels}

The differences in lipid profile levels as related to the $A P O E$ allele groups $(\varepsilon 2, \varepsilon 3$ and $\varepsilon 4)$ and $\mathrm{AF}$ were shown in Table 4. Patients carrying the E2/E4 genotype $(n=27)$ were excluded for the reverse influence in lipid metabolism by $\varepsilon 2$ and $\varepsilon 4$ alleles. The lipid levels depended significantly on $\mathrm{AF}$ and $A P O E$ allele groups for TG, TC, LDL-C and Apo-B (all $P<0.001$ ), and statistically significant interactions between $\mathrm{AF}$ and $A P O E$ allele were observed in the above 4 variables (TG, $F=4.478, P=0.012$; TC, $F=6.189, P=0.002$; LDL-C, $F=3.717, P=0.025$; Apo-B, $F=4.529, P=0.011$, respectively). The result also showed that there was a significant difference in levels of HDL-C between APOE allele groups $(P=0.018)$ but insignificant in $\operatorname{AF}(P=0.264)$. On finding this, a Tukey procedure was performed to test the simple main effects. The results revealed that TG levels for $\varepsilon 2$ carrier with $\mathrm{AF}$ were higher than that for $\varepsilon 2$ carrier without $\mathrm{AF}(F=$ 10.698, $P<0.001$ ) (Fig. 4). Similar results were obtained concerning TG levels for $\varepsilon 4$ carrier $(F=15.118, P<$ 0.001). Additionally, a Tukey post-hoc test of the simple main effects showed that regarding TC, LDL-C and Apo-B levels, patients with AF were significantly higher than those without $\mathrm{AF}$ in all $3 A P O E$ allele groups (all $P<0.05)$.

\section{Assessing risk factors for AF with logistic regression}

A multiple logistic regression test was used to evaluate the independent effect of the categorical variables (age, DBP, APOE- 44 carrier, TC, TG, LDL-C, Apo-B) on the risk of AF (Table 5). These clear associations between

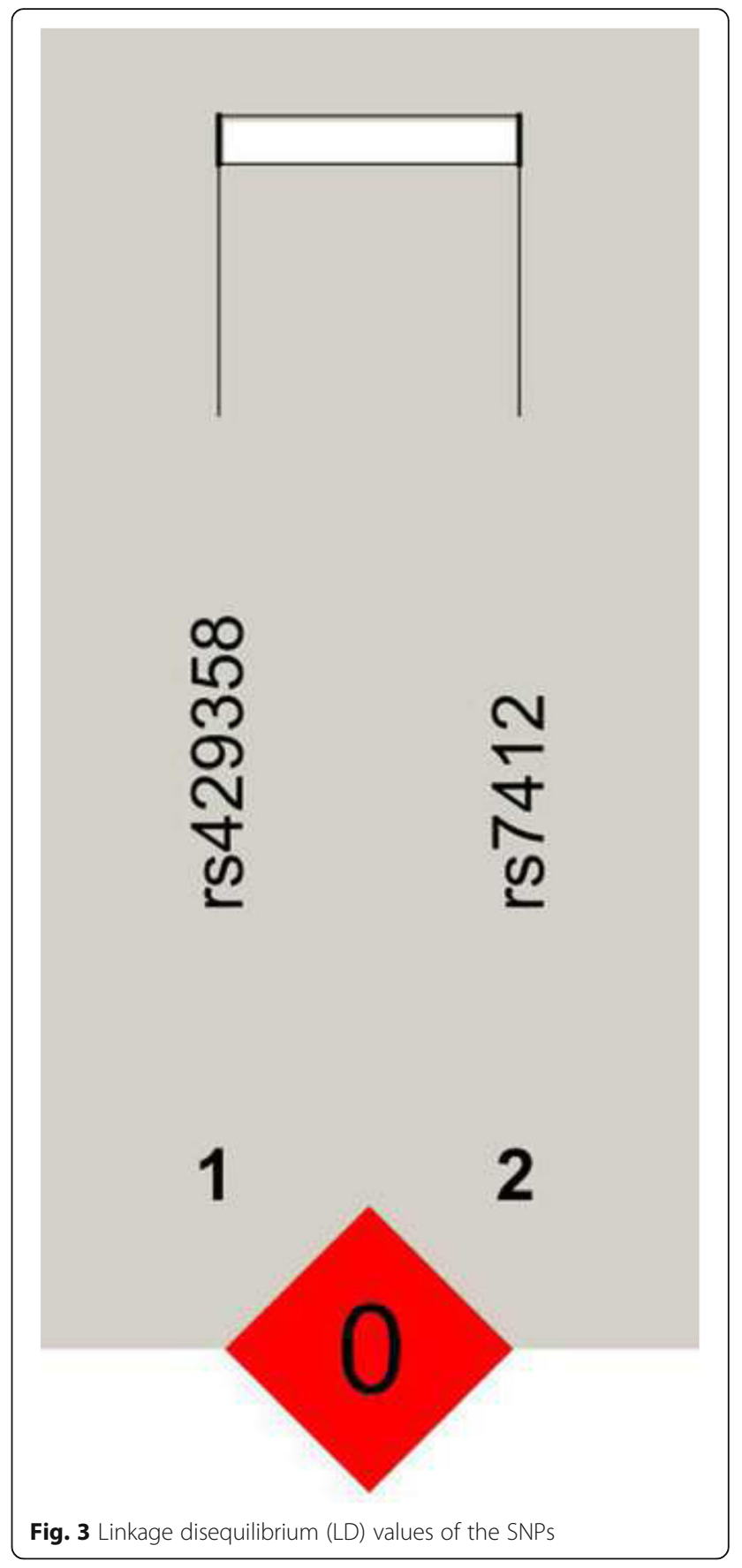

categorical variables and AF were seen on logistic regression analysis with the non-adjusted model. After adjusting for the quantitative variables, such as the echocardiography results (LAD, LVDd, LVSd, and LVEF), laboratory data (ALT, AST, UN, Scr and UA), and categorical variables including concomitant drugs (ACEIs, BBs, MRAs, digoxin and diuretics), CAD and $\mathrm{HF}$, the consequences indicated that age $\geq 65$ years (OR $2.848,95 \%$ CI 1.894-4.283, $P<0.001$ ), high DBP (OR 1.556, $95 \%$ CI $1.080-2.240, P=0.018$ ), high TG (OR 
Table 4 Lipid levels and the results of two-way ANOVA with AF groups and the three APOE alleles

\begin{tabular}{|c|c|c|c|c|c|c|c|}
\hline & \multicolumn{3}{|l|}{$A P O E$ allele groups } & \multicolumn{2}{|l|}{ AF groups } & \multicolumn{2}{|c|}{$\begin{array}{l}\text { ANOVA } \\
\text { interaction } \\
\text { (AF and } \\
A P O E \\
\text { alleles) }\end{array}$} \\
\hline & $\varepsilon 2(n=203)$ & $\varepsilon 3(n=758)$ & $\varepsilon 4(n=379)$ & AF $(n=693)$ & Non-AF $(n=647)$ & $F$ & $P$ \\
\hline $\begin{array}{l}\text { TC (mmol/ } \\
\text { L) }\end{array}$ & $\begin{array}{l}3.737(0.075 ; 3.590- \\
3.884)\end{array}$ & $\begin{array}{l}4.253(0.039 ; 4.177- \\
4.329)\end{array}$ & $\begin{array}{l}4.512(0.055 ; 4.404- \\
4.621)\end{array}$ & $\begin{array}{l}4.404(0.047 ; 4.312- \\
4.496)\end{array}$ & $\begin{array}{l}3.930(0.048 ; 3.386- \\
4.025)\end{array}$ & 6.189 & 0.002 \\
\hline $\begin{array}{l}\text { TG } \\
(\mathrm{mmol} / \mathrm{L})\end{array}$ & $\begin{array}{l}1.045(0.050 ; 0.947- \\
1.143)\end{array}$ & $\begin{array}{l}1.264(0.026 ; 1.214- \\
1.315)\end{array}$ & $\begin{array}{l}1.490(0.037 ; 1.417- \\
1.562)\end{array}$ & $\begin{array}{l}1.380(0.031 ; 1.319- \\
1.441)\end{array}$ & $\begin{array}{l}1.153(0.032 ; 1.090- \\
1.216)\end{array}$ & 4.478 & 0.012 \\
\hline $\begin{array}{l}\mathrm{HDL}-\mathrm{C} \\
(\mathrm{mmol} / \mathrm{L})\end{array}$ & $\begin{array}{l}1.275(0.027 ; 1.223- \\
1.327)\end{array}$ & $\begin{array}{l}1.240(0.014 ; 1.213- \\
1.267)\end{array}$ & $\begin{array}{l}1.188(0.020 ; 1.149- \\
1.226)\end{array}$ & $\begin{array}{l}1.248(0.017 ; 1.215- \\
1.280)\end{array}$ & $\begin{array}{l}1.221(0.017 ; 1.187- \\
1.254)\end{array}$ & 0.214 & 0.808 \\
\hline $\begin{array}{l}\text { LDL-C } \\
(\mathrm{mmol} / \mathrm{L})\end{array}$ & $\begin{array}{l}1.857(0.053 ; 1.753- \\
1.962)\end{array}$ & $\begin{array}{l}2.340(0.028 ; 2.286- \\
2.394)\end{array}$ & $\begin{array}{l}2.566(0.039 ; 2.488- \\
2.643)\end{array}$ & $\begin{array}{l}2.406(0.033 ; 2.340- \\
2.471)\end{array}$ & $\begin{array}{l}2.103(0.034 ; 2.035- \\
2.170)\end{array}$ & 3.717 & 0.025 \\
\hline $\begin{array}{l}\text { Apo-A1 } \\
\text { (g/L) }\end{array}$ & $\begin{array}{l}1.066(0.023 ; 1.020- \\
1.111)\end{array}$ & $\begin{array}{l}1.074(0.012 ; 1.050- \\
1.097)\end{array}$ & $\begin{array}{l}1.066(0.017 ; 1.033- \\
1.099)\end{array}$ & $\begin{array}{l}1.049(0.014 ; 1.021- \\
1.077)\end{array}$ & $\begin{array}{l}1.088(0.015 ; 1.059- \\
1.117)\end{array}$ & 0.264 & 0.768 \\
\hline $\begin{array}{l}\text { Apo-B } \\
(\mathrm{g} / \mathrm{L})\end{array}$ & $\begin{array}{l}0.620(0.017 ; 0.587- \\
0.654)\end{array}$ & $\begin{array}{l}0.763(0.009 ; 0.745- \\
0.780)\end{array}$ & $\begin{array}{l}0.833(0.013 ; 0.808- \\
0.857)\end{array}$ & $\begin{array}{l}0.785(0.011 ; 0.764- \\
0.806)\end{array}$ & $\begin{array}{l}0.692(0.011 ; 0.670- \\
0.713)\end{array}$ & 4.529 & 0.011 \\
\hline
\end{tabular}

Mean (SD; range)

AF: atrial fibrillation

TC: total cholesterol

TG: triglyceride

HDL-C: high-density lipoprotein cholesterol

LDL-C: low-density lipoprotein cholesterol

Apo-A1: apolipoprotein A1

Apo-B: apolipoprotein B

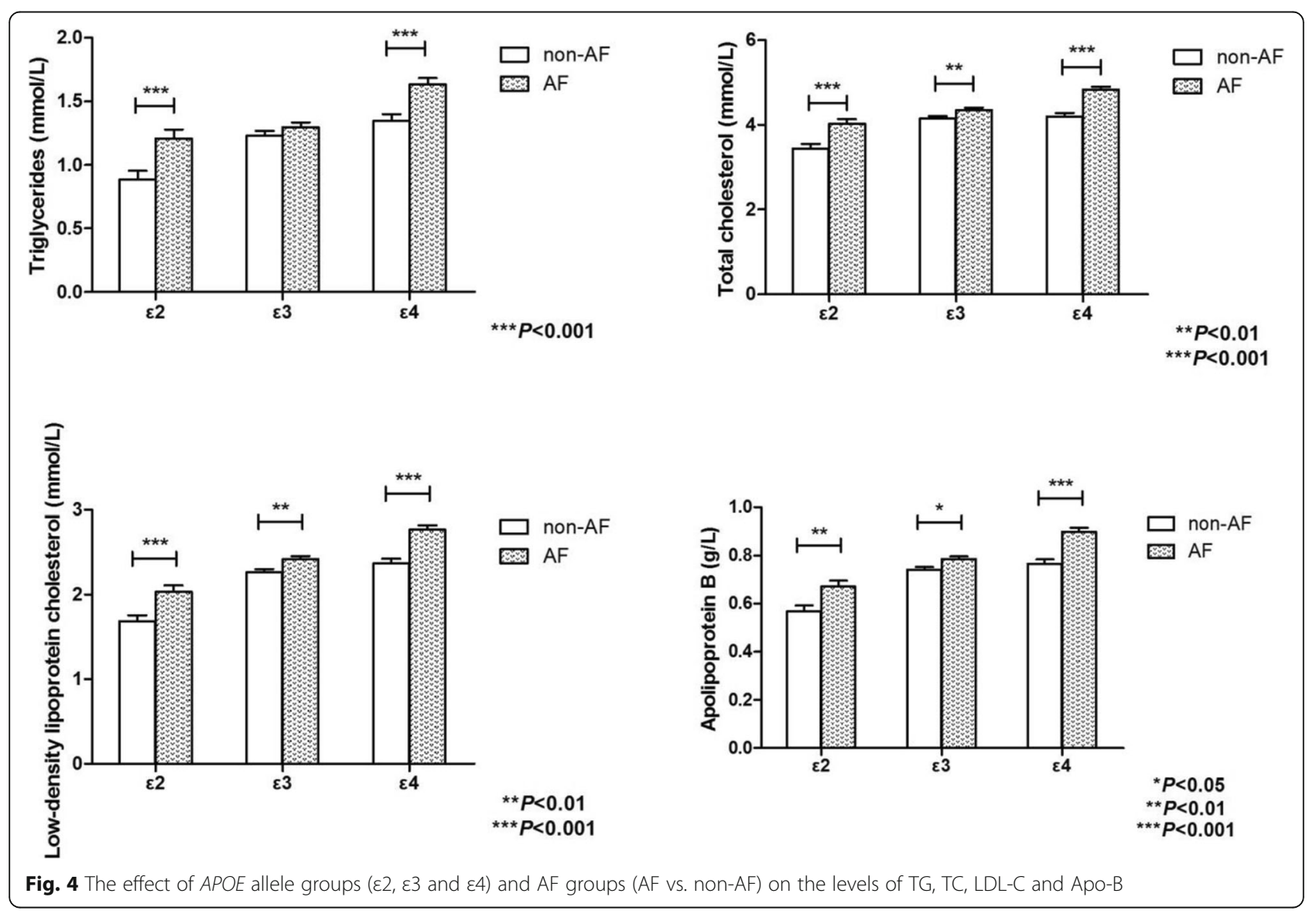


Table $\mathbf{5}$ Logistic regression analysis for risk factors of AF in the study participants

\begin{tabular}{|c|c|c|c|c|c|}
\hline Parameters & No. subjects & $P$ & $\begin{array}{l}\text { Non-adjusted } \\
\text { OR(95\% CI) }\end{array}$ & $P$ & $\begin{array}{l}\text { Adjusted } \\
\text { OR(95\% Cl) }\end{array}$ \\
\hline \multicolumn{6}{|l|}{ Age } \\
\hline$(<65 y)$ & 396 & & (Ref.) & & (Ref.) \\
\hline$(\geq 65 y)$ & 971 & $<0.001$ & $2.937(2.298-3.754)$ & $<0.001$ & $2.848(1.894-4.283)$ \\
\hline \multicolumn{6}{|l|}{ DBP } \\
\hline$(<90 \mathrm{~mm} \mathrm{Hg})$ & 952 & & (Ref.) & & (Ref.) \\
\hline$(\geq 90 \mathrm{~mm} \mathrm{Hg})$ & 415 & $<0.001$ & $1.471(1.166-1.857)$ & 0.018 & $1.556(1.080-2.240)$ \\
\hline \multicolumn{6}{|l|}{$A P O E-\varepsilon 4$ carrier } \\
\hline no & 961 & & (Ref.) & & (Ref.) \\
\hline yes & 406 & 0.053 & $1.258(0.997-1.588)$ & 0.683 & $1.079(0.748-1.558)$ \\
\hline \multicolumn{6}{|l|}{ TC } \\
\hline$(<5.2 \mathrm{mmol} / \mathrm{L})$ & 1141 & & (Ref.) & & (Ref.) \\
\hline$(\geq 5.2 \mathrm{mmol} / \mathrm{L})$ & 226 & $<0.001$ & $4.305(3.066-6.045)$ & $<0.001$ & $3.879(2.003-7.513)$ \\
\hline \multicolumn{6}{|l|}{ TG } \\
\hline$(<1.7 \mathrm{mmol} / \mathrm{L})$ & 1104 & & (Ref.) & & (Ref.) \\
\hline$(\geq 1.7 \mathrm{mmol} / \mathrm{L})$ & 263 & $<0.001$ & $1.823(1.382-2.406)$ & 0.028 & $1.596(1.053-2.419)$ \\
\hline \multicolumn{6}{|l|}{ LDL-C } \\
\hline$(<3.4 \mathrm{mmol} / \mathrm{L})$ & 1240 & & (Ref.) & & (Ref.) \\
\hline$(\geq 3.4 \mathrm{mmol} / \mathrm{L})$ & 127 & $<0.001$ & $6.522(3.913-10.872)$ & 0.596 & $1.308(0.485-3.527)$ \\
\hline \multicolumn{6}{|l|}{ Apo-B } \\
\hline$(<1.1 \mathrm{~g} / \mathrm{L})$ & 1242 & & (Ref.) & & (Ref.) \\
\hline$(\geq 1.1 \mathrm{~g} / \mathrm{L})$ & 125 & $<0.001$ & $3.983(2.550-6.222)$ & 0.459 & $1.380(0.589-3.233)$ \\
\hline
\end{tabular}

OR in adjusted model was adjusted for LAD, LVDd, LVSd, LVEF, ALT, AST, UN, Scr, UA, CAD, HF, use of ACEIs, BBs, MRAs, digoxin and diuretics

OR: odds ratio; $\mathrm{Cl}$ : confidence interval. Other abbreviations see in Tables 1 and 2

1.596, $95 \%$ CI 1.053-2.419, $P=0.028)$ and high TC (OR $3.879,95 \%$ CI $2.003-7.513, P<0.001)$ represented independent risk factors for $\mathrm{AF}$, but not the $A P O E$ gene SNPs (rs7412 and rs429358) (OR 1.079, $95 \%$ CI 0.748$1.558, P=0.683)$.

\section{Discussion}

AF represents the most common cardiac arrhythmia caused by atrial electrical remodeling, which leads to the inability to coordinate the contraction and relaxation of the atrium and constitutes a major cause of morbidity. It has been found to tightly link with a higher risk of hospitalization, cardiovascular mortality and cognitive impairment in individuals [24]. AF is also a major health care challenge with an increasing burden with age [25]. Evidence from previous studies suggests that many genes and/or environmental factors may have a combined influence on the occurrence and evolvement of AF [26].

Hypertension and AF frequently coexist, not only because hypertension increases the incidence of new-onset of AF, but also because those two entities share common risk factors and conditions that increase the incidence of both. Hypertension increases the risk of AF occurrences through hemodynamic and non-hemodynamic mechanisms. Uncontrolled high blood pressure increases left ventricular wall load by increasing left ventricular wall tension [27]. Over time, cardiac hypertrophy becomes morbid, and the heart can no longer meet the increasing mechanical workload, resulting in dilation [28]. Diastolic dysfunction causes myocardial fibrosis [29], which may lead to left atrial structure and function are altered [30]. Specifically, structural remodeling leads to electrolytic dissociation and local conduction heterogeneity between muscle bundles, which promotes the occurrence and perpetuation of AF [31].

Many research studies were conducted to discover promising genetic susceptibility markers of AF. With the progress in genome-wide association (GWAS) analysis in recent years, genomics has made considerable progress in the prediction of complex human diseases, such as CAD and AF [32]. To date, over 50 pathogenic gene mutations have been revealed to cause AF, which mainly involve cellular signal molecules [33], myocardial structural proteins [34], ion [35] and gap junction channels [36]. Hsu et al. [34] reported that subjects with AF carrying the $\mathrm{ALDH} 2 * 2$ polymorphism showed more severe oxidative stress in their atria compared with non-carriers and suggested that $A L D H 2$ may protect from AF-related 
remodeling. In a single-center retrospective study, Okamura and colleagues [36] analyzed the SNPs reported in a GWAS analysis of patients with persistent AF and demonstrated that the GJA1 SNP rs1015451 has increased the risk for a higher heart rate during AF. Furthermore, Liu et al. [37] reported that the ACE2 SNP rs4646188 was related to a larger left atrial end-systolic diameter and associated with a higher AF risk among Uygur patients. A recent retrospective study enrolled 155 Mongolian descent patients and revealed that the $A B C B 1$ gene polymorphism may help to achieve a rational drug utilization due to the rs1128503 locus variations, which were linked to rivaroxaban concentration [38]. A Mendelian randomization study by Wang et al. [39] revealed the circulating GDF-15 levels to be significantly related to the increased risk of $\mathrm{CAD}$ and $\mathrm{AF}$, which may optimize strategy for AF treatment.

As a well-documented risk factor for cardiovascular disease, obesity accounts for nearly one-fifth of patients with AF [40]. It has been highlighted by demographic surveys to be an important component of the AF prevention and management strategies [41]. A previously published study revealed that weight reduction through bariatric surgery may reduce the risk for AF development by approximately one-third among obese subjects [42]. Since the $A P O E$ gene has a prominent role in lipoprotein transformation and metabolism, there may be a potential interrelation that probably exists in the $A P O E$ gene polymorphism and AF. After followed for 2 years, a prospective cohort study found that the interaction between permanent non-valvular $\mathrm{AF}$ and $A P O E$ \&4 genotype was linked with a higher risk of cognitive impairment [43], which suggested that $A P O E$ \&4 genotype may participate in the occurrence of AF through some mechanism in Alzheimer's disease. Besides, after whole-exome-based transcriptome analysis of the transcript profiles in the left and right atrium, Tsai et al. reported that AF was associated with the upregulation of the $A P O E$ gene, provided evidence that the $A P O E$ gene may be associated with AF incidence [44]. In recent years, epicardial fat has been identified to be closely linked to the occurrence, severity and even recurrence of AF through several epidemiological and clinical studies [10]. As a type of visceral adipose tissue, epicardial fat is closely adjacent to the coronary artery and myocardium. In a pathological state, epicardial adipose tissue may lead to atrial electrophysiological alteration through infiltration, which may cause AF. Huang et al. conducted a series of studies to assess ApoE expression levels in different adipose tissue depots from multiple species, indicated that in baboons, evaluation of ApoE expression is higher in epicardial adipocytes [45]. APOE $\varepsilon 4$ allele may be related to epicardial fat thickening, which is closely linked with AF occurrence. In this study, the analysis results indicated that the lipid levels depended significantly on AF and $A P O E$ allele groups for TG, TC, LDL$\mathrm{C}$ and Apo-B (all $P<0.001$ ), and statistically significant interactions between $\mathrm{AF}$ and $A P O E$ allele were observed in the above 4 variables, which indicates the potential correlations in the lipid profile, $A P O E$ genotypes and pathogenesis of AF, although the $A P O E$ gene SNPs (rs429358 and rs7412) were not significant independent risk factors for AF incidence. Based on the complex mechanism of $\mathrm{AF}$, the $A P O E$ gene polymorphism may only participate in some links cooperatively, rather than being the main influencing factor in the development of AF. Moreover, other SNPs of the APOE gene were not included in this study. A large-scale set of participants is required to further investigate the association between the $A P O E$ gene and AF.

Multiple risk factors have been well-documented for the prevalence of AF. However, the relationship between the lipid profile and development of AF remains uncertain. In a racially diverse, communitybased, prospective cohort study, high levels of HDL-C were found to reduce the risk of AF, while high TG concentration was revealed to higher risk for $\mathrm{AF}$, and TC and LDL-C were not linked to the risk of AF [46]. An observational study provided evidence that compared with subjects without AF, patients with AF had lower levels of TC, LDL-C and HDL-C, and suggested that low HDL-C levels were significantly associated with a new occurrence of AF [47]. In contrast, after an average of 3.5 years of follow-up, the authors revealed that the HDL-C and TG levels were not correlated with new-onset AF [48]. Inconsistent with the above-mentioned results, the current study showed that high levels of TC and TG, but not HDL-C, were significant independent risk factors for AF. The inconsistent outcomes of different studies may be caused by regional and ethnic discrepancies in the study subjects, socio-demographic composition, sample size or complex environment-genotype-phenotype interactions. Previous studies have confirmed that long-term hyperlipidemia may influence cardiac function and electrophysiological activity [49, 50], involving the alteration of the membrane lipid bilayer as well as modulation of intracellular calcium ions and isoform expression patterns of the myosin heavy chain [51]. The alternate expression in a series of crucial proteins has confirmed the negative effect of hyperlipidemia on the heart $[52,53]$. Main mechanisms include the following. First, high levels of TC lead to systemic oxidative stress and a proinflammatory state [54]. There are a number of evidence that point to a role for inflammatory processes in the pathophysiology of AF. Inflammatory effects on the atrial myocardium may facilitate arrhythmogenesis 
[55]. Oxidative stress is implicated in the pathophysiology of atrial remodeling, which promotes the development of atrial fibrillation [4]. Second, hyperlipidemia downregulates autophagy and promotes the apoptosis of cardiomyocytes, which may be responsible for the loss of cardioprotection [56]. Third, $\mathrm{Ca}^{2+} /$ calmodulin-dependent protein kinase II (CaMKII) acts as a crucial factor in regulating the normal electrophysiology and structure of cardiomyocytes. Under hyperlipidemia conditions, the increased expression of CaMKII in cardiomyocytes induces their electrical remodeling and triggers arrhythmia [57]. All these mechanisms were closely associated with the incidence of AF. Notably, there was no significant association between LDL-C and AF after adjusting for other parameters (OR: 1.308, $95 \%$ CI: 0.485-3.527, $P=0.596)$. The relationship between LDL-C and AF was unexpected and no clear mechanism could be presented. Several possible mechanisms may account for the result. First, clinical and subclinical hyperthyroidism may be potentially responsible for the LDL-C reduction as well as the promotion of AF. Thyroid hormone promotes cholesterol catabolism and excretion, lowers circulating levels of LDL-C. Hyperthyroidism is also known to be an independent risk factor for AF. Unfortunately, the lack of thyroid functions data in the current study made it difficult to confirm the association. Second, inflammation may be an important link between cholesterol and AF. Due to the action of inflammatory cytokines, the levels of TC, LDL-C and HDL-C were decreased, while TG was increased in inflammation [58]. Therefore, low cholesterol levels can reflect the level of inflammation in vivo. A low level of LDL-C probably contributes to the pathogenesis of AF via enhancing inflammatory response, since chronic inflammation has been recognized as significantly related to the incidence and perpetuation of AF [59]. Third, lipids are the structural components of cell membranes. Balse et al. showed that changes in cholesterol levels may alter membrane structure and affect the function of ion channels and receptors. This can affect electrical gradient and resting potential across the membranes and potentially participate in the occurrence of AF [60].

Taken together, the results suggested that more attention should be paid to abnormal lipid levels by clinicians, not only as a risk factor for adverse cardiovascular outcomes, but also as a possible risk marker for AF, especially in elderly patients with higher DBP, TC or TG. These findings may provide additional evidence to distinguish high-risk AF patients to intervene before the symptoms appear in clinical practice and contribute to establishing personalized early interference strategies in primary healthcare facilities for people with a potential risk of AF.

\section{Comparisons with other studies and what does the} current work add to the existing knowledge

In terms of novelty, a considerable number of studies have reported on the related genes of AF incidence, and it is the first time to explore the relationship between $A P O E$ gene polymorphism and AF among the Hakka population, provides new data for Hakka population research. A supplement to existing knowledge, the current study revealed that high levels of DBP, TC and TG were also significant independent risk factors for AF incidence in this study patients, not only closely linked with cardiovascular events.

\section{Strengths and limitations}

This work is the first to investigate the association between the $A P O E$ gene polymorphism and lipid profile on the one side, and the risk of AF in the Hakka ethnic of southern China on the other side. The SNPs of the $A P O E$ gene (rs7412 and rs429358) were not significant risk for AF in the current study. By including and adjusting for the factors of comprehensive clinical characteristics, such as the echocardiographic parameters, laboratory test data and lipid profile, the results indicated that aged over 65 years, high levels of DBP, TC and TG were significant independent risk factors for AF in this study participants.

There are several limitations to this study. Firstly, for diseases with complex influencing factors, it has always been challenging to explore the relationship between a particular gene allele and such diseases. Hence, further genetic studies on other SNPs of the APOE gene are necessary to elucidate the precise association between the $A P O E$ gene polymorphism and AF. Plus, in addition to the moderating effect on the lipid profile levels, the antioxidant properties of the $A P O E$ genotypes should also be considered. Secondly, given the genetic diversity of different ethnic and regional populations and as a singlecenter study, these findings may not be applicable to other areas or ethnicities. Thirdly, lacking data on thyroid function and other echocardiographic parameters (e.g., left ventricular mass) might confound the results. Finally, owing to the retrospective study design, it is subject to the limitations inherent which were also noted in the previous study, possible selection bias has existed.

\section{Conclusions}

In summary, the study suggested that well-established risk factors for CAD, older age as well as high levels of DBP, TC and TG were also significant independent risks for AF in the Hakka ethnic of southern Chinese. Furthermore, the levels of TG, TC, LDL-C and Apo-B depended significantly on $\mathrm{AF}$ and $A P O E$ allele groups, and statistically significant interactions between $\mathrm{AF}$ and $A P O E$ allele were observed in the above 4 variables, 
although the APOE gene SNPs (rs429358 and rs7412) were not significant independent risk factors for AF incidence in the study. The observed correlation needs to be further validated in future studies.

\section{Abbreviations}

AF: atrial fibrillation; GWAS: genome-wide association study; SBP: systolic blood pressure; DBP: diastolic blood pressure; CAD: coronary artery disease; HF: heart failure; LAD: left atrium diameter; LVDd: left ventricular end-diastolic diameter; LVSd: left ventricular end-systolic diameter; LVEF: left ventricular ejection fractions; TC: total cholesterol; TG: triglyceride; HDL-C: high-density lipoprotein cholesterol; LDL-C: low-density lipoprotein cholesterol; ApoA1: apolipoprotein A1; Apo-B: apolipoprotein B; ALT: alanine aminotransferase; AST: aspartate aminotransferase; UN: urea nitrogen; Scr: serum creatinine; UA: uric acid; CRP: c-reactive protein; WBC: white blood cell; ACEl: angiotensin-converting enzyme inhibitor; ARB: angiotensin receptor blocker; BB: $\beta$-receptor blocker; MRA: mineralocorticoid antagonist; OR: odds ratio; $\mathrm{Cl}$ : confidence interval; SD: standard deviation; SNP: single nucleotide polymorphism; CHD: coronary heart disease; PCR: polymerase chain reaction; LD: linkage disequilibrium

\section{Acknowledgements}

The authors would like to thank other colleagues who were not listed in the authorship of Center for Cardiovascular Diseases, Clinical Core Laboratory and Center for Precision Medicine, Meizhou People's Hospital (Huangtang Hospital), for their helpful comments on the manuscript. We would like to thank all of the participants in this study, and express our gratitude to EditSprings (https://www.editsprings.com/) for the expert linguistic services provided.

\section{Authors' contributions}

Zhixiong Zhong and Jingyuan Hou conceived and designed the experiments; Qiaoting Deng recruited subjects and collected clinical data. Xunwei Deng conducted the laboratory testing, analyzed the results, and wrote this paper. All of the authors gave final approval of the submitted version.

\section{Funding}

This study was supported by the Guangdong Provincial Key Laboratory of Precision Medicine and Clinical Translational Research of Hakka Population (grant no. 2018B030322003).

\section{Availability of data and materials}

Data and material would be supplied based on reasonable request.

\section{Declarations}

\section{Ethics approval and consent to participate}

The study protocol was performed following the ethical guidelines of the 1975 Declaration of Helsinki. The institutional review board and ethical committee of the Meizhou Peoples' Hospital (No. MPH-HEC 2021-C-19) approved the study. All participants provided written informed consent before their enrollment in the study.

\section{Consent for publication}

Not applicable.

\section{Competing interests}

The authors declare that they have no conflict of interest.

\section{Author details}

${ }^{1}$ Department of Research Experimental Center, Meizhou People's Hospital (Huangtang Hospital), Meizhou, P. R. China. ${ }^{2}$ Guangdong Provincial Key Laboratory of Precision Medicine and Clinical Translational Research of Hakka Population, Meizhou, P. R. China. ${ }^{3}$ Guangdong Provincial Engineering and Technology Research Center for Molecular Diagnostics of Cardiovascular Diseases, Meizhou, P. R. China. ${ }^{4}$ Meizhou Academy of Medical Sciences Cardiovascular Disease Research Institute, Meizhou, P. R. China. ${ }^{5}$ Center for Cardiovascular Diseases, Meizhou People's Hospital (Huangtang Hospital),
Meizhou, P. R. China. ${ }^{6}$ Meizhou People's Hospital (Huangtang Hospital), No 63 Huangtang Road, Meijiang District, 514031 Meizhou, China.

Received: 4 June 2021 Accepted: 10 September 2021 Published online: 29 September 2021

\section{References}

1. Li YG, Pastori D, Farcomeni A, Yang PS, Jang E, Joung B, et al. A Simple Clinical Risk Score (C(2)HEST) for Predicting Incident Atrial Fibrillation in Asian Subjects: Derivation in 471,446 Chinese Subjects, With Internal Validation and External Application in 451,199 Korean Subjects. Chest. 2019; 155(3):510-8

2. Lau DH, Linz D, Sanders P. New Findings in Atrial Fibrillation Mechanisms. Cardiac electrophysiology clinics. 2019;11(4):563-71.

3. Volgman AS, Dunn P, Sundberg A, Conard S, Chakravarty P, Htway Z, et al. Risk Factors for Symptomatic Atrial Fibrillation-Analysis of an Outpatient Database. Journal of atrial fibrillation. 2019;12(1):2141.

4. Korantzopoulos P, Letsas K, Fragakis N, Tse G, Liu T. Oxidative stress and atrial fibrillation: an update. Free Radic Res. 2018;52(11-12):1199-209.

5. Karam BS, Chavez-Moreno A, Koh W, Akar JG, Akar FG. Oxidative stress and inflammation as central mediators of atrial fibrillation in obesity and diabetes. Cardiovascular diabetology. 2017;16(1):120.

6. Thomas L, Abhayaratna WP. Left Atrial Reverse Remodeling: Mechanisms, Evaluation, and Clinical Significance. JACC Cardiovascular imaging. 2017; 10(1):65-77

7. Kalita S, Khandelwal S, Madan J, Pandya H, Sesikeran B, Krishnaswamy K. Almonds and cardiovascular health: a review. Nutrients. 2018;10(4):468.

8. Pires A, Sena C, Seiça R. Dyslipidemia and cardiovascular changes in children. Curr Opin Cardiol. 2016;31(1):95-100.

9. Ahotupa M. Oxidized lipoprotein lipids and atherosclerosis. Free Radic Res. 2017:51(4):439-47.

10. Wong CX, Ganesan AN, Selvanayagam JB. Epicardial fat and atrial fibrillation: current evidence, potential mechanisms, clinical implications, and future directions. Eur Heart J. 2017;38(17):1294-302.

11. Nalliah CJ, Sanders P, Kottkamp H, Kalman JM. The role of obesity in atria fibrillation. Eur Heart J. 2016;37(20):1565-72.

12. Chaumont C, Suffee N, Gandjbakhch E, Balse E, Anselme F, Hatem SN. Epicardial origin of cardiac arrhythmias: clinical evidences and pathophysiology. Cardiovasc Res. 2021:cvab213. Online ahead of print.

13. Ilveskoski $E$, Järvinen $O$, Sisto T, Karhunen PJ, Laippala P, Lehtimäki T. Apolipoprotein E polymorphism and atherosclerosis: association of the epsilon4 allele with defects in the internal elastic lamina. Atherosclerosis. 2000;153(1):155-60.

14. Hou J, Deng Q, Guo X, Deng X, Zhong W, Zhong Z. Association between apolipoprotein $\mathrm{E}$ gene polymorphism and the risk of coronary artery disease in Hakka postmenopausal women in southern China. Lipids Health Dis. 2020;19(1):139.

15. Karahan Z, Uğurlu M, Uçaman B, Uluğ AV, Kaya I, Çevik K, et al. Relation between Apolipoprotein E Gene Polymorphism and Severity of Coronary Artery Disease in Acute Myocardial Infarction. Cardiol Res Pract. 2015;2015: 363458

16. Raygani AV, Zahrai M, Raygani AV, Doosti M, Javadi E, Rezaei M, et al. Association between apolipoprotein E polymorphism and Alzheimer disease in Tehran, Iran. Neurosci Lett. 2005:375(1):1-6.

17. Lv P, Zheng Y, Huang J, Ke J, Zhang H. Association of Apolipoprotein E Gene Polymorphism with Ischemic Stroke in Coronary Heart Disease Patients Treated with Medium-intensity Statins. Neuropsychiatr Dis Treat. 2020;16:2459-66.

18. Chen XR, Shao Y, Sadowski MJ. Segmented Linear Mixed Model Analysis Reveals Association of the APOE\&4 Allele with Faster Rate of Alzheimer's Disease Dementia Progression. Journal of Alzheimer's disease: JAD; 2021.

19. Dyer AH, Murphy C, Lawlor B, Kennelly SP. For The Nilvad Study G. Longterm antipsychotic use and cognitive decline in community-dwelling older adults with mild-moderate Alzheimer disease: Data from NILVAD. Int J Geriatr Psychiatr. 2021;gps.5591. Online ahead of print.

20. Comments on the. 2020 ESC/EACTS guidelines for the management of atrial fibrillation. Revista espanola de cardiologia (English ed). 2021;74(5): $378-83$

21. James PA, Oparil S, Carter BL, Cushman WC, Dennison-Himmelfarb C, Handler J, et al. 2014 evidence-based guideline for the management of 
high blood pressure in adults: report from the panel members appointed to the Eighth Joint National Committee (JNC 8). Jama. 2014;311(5):507-20.

22. [Chinese guidelines on prevention and treatment of dyslipidemia in adults]. Zhonghua xin xue guan bing za zhi. 2007:35(5):390-419.

23. Zhong L, Li Q, Jiang Y, Cheng D, Liu Z, Wang B, et al. The ApoB/ApoA1 ratio is associated with metabolic syndrome and its components in a Chinese population. Inflammation. 2010;33(6):353-8.

24. Viticchi G, Falsetti L, Vernieri F, Altamura C, Altavilla R, Luzzi S, et al. Apolipoprotein E genotype and cerebrovascular alterations can influence conversion to dementia in patients with mild cognitive impairment. Journal of Alzheimer's disease: JAD. 2014;41(2):401-10.

25. Lloyd-Jones DM, Wang TJ, Leip EP, Larson MG, Levy D, Vasan RS, et al. Lifetime risk for development of atrial fibrillation: the Framingham Heart Study. Circulation. 2004;110(9):1042-6.

26. Deng H, Guo P, Zheng M, Huang J, Xue Y, Zhan X, et al. Epidemiological Characteristics of Atrial Fibrillation in Southern China: Results from the Guangzhou Heart Study. Sci Rep. 2018;8(1):17829.

27. Askin L, Tasolar H, Aksu U, Cetin M, Uslu A, Tanboga HI, et al. Discerning the relationship between left ventricular geometry, high-sensitivity troponin $\mathrm{T}$, and nondipper hypertension. Blood pressure monitoring. 2018;23(1):12-8.

28. Ozal E, Sahin I, Bolat I, Pusuroglu H, Avci II, Akgul O, et al. Visfatin levels are increased in patients with resistant hypertension and are correlated with left ventricular hypertrophy. Blood pressure monitoring. 2017;22(3):137-42.

29. Nattel S, Harada M. Atrial remodeling and atrial fibrillation: recent advances and translational perspectives. J Am Coll Cardiol. 2014;63(22):2335-45.

30. Manolis AJ, Rosei EA, Coca A, Cifkova R, Erdine SE, Kjeldsen S, et al. Hypertension and atrial fibrillation: diagnostic approach, prevention and treatment. Position paper of the Working Group 'Hypertension Arrhythmias and Thrombosis' of the European Society of Hypertension. Journal of hypertension. 2012;30(2):239-52.

31. McCauley MD, Hong L, Sridhar A, Menon A, Perike S, Zhang M, et al. Ion Channel and Structural Remodeling in Obesity-Mediated Atrial Fibrillation. Circulation Arrhythmia electrophysiology. 2020;13(8):e008296.

32. Yong SY, Raben TG, Lello L, Hsu SDH. Genetic architecture of complex traits and disease risk predictors. Sci Rep. 2020;10(1):12055.

33. Mosley JD, Levinson RT, Farber-Eger E, Edwards TL, Hellwege JN, Hung AM, et al. The polygenic architecture of left ventricular mass mirrors the clinical epidemiology. Sci Rep. 2020;10(1):7561.

34. Hsu LA, Tsai FC, Yeh YH, Chang CJ, Kuo CT, Chen WJ, et al. Aldehyde Dehydrogenase 2 Ameliorates Chronic Alcohol Consumption-Induced Atrial Fibrillation through Detoxification of 4-HNE. Int J Mol Sci. 2020;21(18):6678.

35. Schmidt C, Ravens U. Genetic background of atrial fibrillation: influence of single-nucleotide polymorphisms. Cardiovascular research. 2020;1 16(9):e106-e8.

36. Okamura S, Onohara Y, Ochi H, Tokuyama T, Hironobe N, Okubo Y, et al. Minor allele of GJA1 gene polymorphism is associated with higher heart rate during atrial fibrillation. Sci Rep. 2021;11(1):2549.

37. Liu C, Pei J, Lai Y, Guan T, Zeyaweiding A, Maimaiti T, et al. Association of ACE2 variant rs 4646188 with the risks of atrial fibrillation and cardioembolic stroke in Uygur patients with type 2 diabetes. BMC Cardiovasc Disord. 2021; 21(1):103.

38. Wang Y, Chen M, Chen H, Wang F. Influence of ABCB1 Gene Polymorphism on Rivaroxaban Blood Concentration and Hemorrhagic Events in Patients With Atrial Fibrillation. Front Pharmacol. 2021;12:639854.

39. Wang Z, Yang F, Ma M, Bao Q, Shen J, Ye F, et al. The impact of growth differentiation factor 15 on the risk of cardiovascular diseases: two-sample Mendelian randomization study. BMC Cardiovasc Disord. 2020;20(1):462.

40. Schnabel RB, Yin X, Gona P, Larson MG, Beiser AS, McManus DD, et al. 50 year trends in atrial fibrillation prevalence, incidence, risk factors, and mortality in the Framingham Heart Study: a cohort study. Lancet. 2015; 386(9989):154-62.

41. Wong CX, Lau DH, Sanders P. Atrial fibrillation epidemic and hospitalizations: how to turn the rising tide? Circulation. 2014;129(23):2361-3.

42. Jamaly S, Carlsson L, Peltonen M, Jacobson P, Sjöström L, Karason K. Bariatric Surgery and the Risk of New-Onset Atrial Fibrillation in Swedish Obese Subjects. J Am Coll Cardiol. 2016;68(23):2497-504.

43. Falsetti L, Viticchi G, Buratti L, Grigioni F, Capucci A, Silvestrini M. Interactions between Atrial Fibrillation, Cardiovascular Risk Factors, and ApoE Genotype in Promoting Cognitive Decline in Patients with Alzheimer's Disease: A Prospective Cohort Study. J Alzheimers Dis. 2018;62(2):713-25.

44. Tsai FC, Lin YC, Chang SH, Chang GJ, Hsu YJ, Lin YM, et al. Differential leftto-right atria gene expression ratio in human sinus rhythm and atrial fibrillation: Implications for arrhythmogenesis and thrombogenesis. Int J Cardiol. 2016;222:104-12.

45. Huang ZH, Espiritu DJ, Uy A, Holterman AX, Vitello J, Mazzone T. Adipose tissue depot-specific differences in adipocyte apolipoprotein E expression. Metabolism. 2011;60(12):1692-701.

46. Alonso A, Yin X, Roetker NS, Magnani JW, Kronmal RA, Ellinor PT, et al. Blood lipids and the incidence of atrial fibrillation: the Multi-Ethnic Study of Atherosclerosis and the Framingham Heart Study. Journal of the American Heart Association. 2014;3(5):e001211.

47. Barkas F, Elisaf M, Korantzopoulos P, Tsiara S, Liberopoulos E. The CHADS(2) and CHA(2)DS(2)-VASc scores predict atrial fibrillation in dyslipidemic individuals: Role of incorporating low high-density lipoprotein cholesterol levels. Int J Cardiol. 2017;241:194-9.

48. Mourtzinis G, Kahan T, Bengtsson Boström K, Schiöler L, Cedstrand Wallin L, Hjerpe P, et al. Relation Between Lipid Profile and New-Onset Atrial Fibrillation in Patients With Systemic Hypertension (From the Swedish Primary Care Cardiovascular Database [SPCCD]). The American journal of cardiology. 2018;122(1):102-7.

49. Fenk S, Fischer M, Strack C, Schmitz G, Loew T, Lahmann C, et al. Successful weight reduction improves left ventricular diastolic function and physical performance in severe obesity. Int Heart J. 2015;56(2):196-202.

50. Pathak RK, Mahajan R, Lau DH, Sanders P. The implications of obesity for cardiac arrhythmia mechanisms and management. Can J Cardiol. 2015;31(2): 203-10.

51. Fauchier $L$, de Labriolle A. Cholesterol levels and cholesterol lowering in idiopathic dilated cardiomyopathy. Eur Heart J. 2005;26(18):1931. author reply -2 .

52. Hondares E, Rosell M, Díaz-Delfín J, Olmos $\mathrm{Y}$, Monsalve $\mathrm{M}$, Iglesias $\mathrm{R}$, et al. Peroxisome proliferator-activated receptor a (PPARa) induces PPARY coactivator 1a (PGC-1a) gene expression and contributes to thermogenic activation of brown fat: involvement of PRDM16. J Biol Chem. 2011;286(50): 43112-22.

53. Castillo RL, Herrera EA, Gonzalez-Candia A, Reyes-Farias M, de la Jara N, Peña JP, et al. Quercetin Prevents Diastolic Dysfunction Induced by a HighCholesterol Diet: Role of Oxidative Stress and Bioenergetics in Hyperglycemic Rats. Oxidative medicine and cellular longevity. 2018;2018: 7239123.

54. Han Q, Yeung SC, Ip MSM, Mak JCW. Dysregulation of cardiac lipid parameters in high-fat high-cholesterol diet-induced rat model. Lipids Health Dis. 2018;17(1):255.

55. Rotter $M$, Jaïs $P$, Vergnes $M C$, Nurden $P$, Takahashi $Y$, Sanders $P$, et al. Decline in C-reactive protein after successful ablation of long-lasting persistent atrial fibrillation. J Am Coll Cardiol. 2006;47(6):1231-3.

56. Giricz Z, Koncsos G, Rajtík T, Varga ZV, Baranyai T, Csonka C, et al. Hypercholesterolemia downregulates autophagy in the rat heart. Lipids Health Dis. 2017;16(1):60.

57. Zhong P, Quan D, Huang Y, Huang H. CaMKII Activation Promotes Cardiac Electrical Remodeling and Increases the Susceptibility to Arrhythmia Induction in High-fat Diet-Fed Mice With Hyperlipidemia Conditions. J Cardiovasc Pharmacol. 2017;70(4):245-54.

58. Khovidhunkit W, Kim MS, Memon RA, Shigenaga JK, Moser AH, Feingold KR, et al. Effects of infection and inflammation on lipid and lipoprotein metabolism: mechanisms and consequences to the host. J Lipid Res. 2004; 45(7):1169-96

59. Patel $\mathrm{P}$, Dokainish $\mathrm{H}$, Tsai $\mathrm{P}$, Lakkis $\mathrm{N}$. Update on the association of inflammation and atrial fibrillation. J Cardiovasc Electrophysiol. 2010;21(9): 1064-70.

60. Balse E, El-Haou S, Dillanian G, Dauphin A, Eldstrom J, Fedida D, et al. Cholesterol modulates the recruitment of Kv1.5 channels from Rab11associated recycling endosome in native atrial myocytes. Proc Natl Acad Sci U S A. 2009;106(34):14681-6.

\section{Publisher's Note}

Springer Nature remains neutral with regard to jurisdictional claims in published maps and institutional affiliations. 